\title{
GA based optimal planning of VAR sources using Fast Voltage Stability Index method
}

\author{
Biplab Bhattacharyya, ShWeta Rani, Ram IshWar Vais, \\ INDRADEO PRATAP BHARTI \\ Department of Electrical Engineering, Indian School of Mines \\ Dhanbad, Jharkhand, India, 826001 \\ e-mail:biplabrec@yahoo.com
}

(Received: 20.01.2016, revised: 07.09.2016)

\begin{abstract}
This paper presents a novel approach for reactive power planning of a connected power network. Reactive power planning is nothing but the optimal usage of all reactive power sources i.e., transformer tap setting arrangements, reactive generations of generators and shunt VAR compensators installed at weak nodes. Shunt VAR compensator placement positions are determined by a FVSI (Fast Voltage Stability Index) method. Optimal setting of all reactive power reserves are determined by a GA (genetic algorithm) based optimization method. The effectiveness of the detection of the weak nodes by the FVSI method is validated by comparing the result with two other wellknown methods of weak node detection like Modal analysis and the $L$-index method. Finally, FVSI based allocation of VAR sources emerges as the most suitable method for reactive power planning.

Key words: active power loss, FVSI method, genetic algorithm, operating cost, reactive power planning, weak nodes
\end{abstract}

\section{Introduction}

Reactive power planning has been one of the most challenging problem to the power system engineers. Expansion of a transmission network is not always possible because of several reasons like cost, right of way etc. Again maintaining good quality of voltage for distribution of power to the consumer is also an important aspect. Sometimes a situation of system collapse is observed even with the slight increase in reactive power demand. Hence, it becomes absolutely necessary for the proper co-ordination and planning of all reactive power sources present in the network. In this paper, main concerns are proper planning and coordination of control variables like transformer tap changers, shunt VAR compensators, generators reactive VAR in an interconnected power system for minimum active power loss as well as minimum operating cost.

A linear programming based optimization method is presented in [1] for optimal reactive power generation of large scale electric power networks. The solution of the reactive power 
problem by optimal placement of a capacitor is discussed in [2]. A modal analysis technique is described in [3] for the determination of weak nodes of a connected power network. The reactive power problem is solved in [4] by injecting reactive power at weak buses of a connected power system. Application of evolutionary programming in reactive power planning is discussed in [5]. A hybrid expert system and simulated annealing based algorithm for the planning of reactive power sources is presented in [6]. A technique for the determination of reactive margin is presented in [7]. Heuristic modal for secured operation of a power system is developed in [8]. A binary search technique and special heuristics are applied for optimal VAR planning in the case of a large scale power system in [9]. Static security constraints and nonprobabilistic uncertainties in load values are considered for optimal reactive power planning in [10]. Two rule based modules are used for voltage profile improvement to alleviate voltage limit violations and for minimization of active power loss in [11]. Comparative analysis of some evolutionary algorithms on reactive power planning for IEEE 30 bus system is discussed in [12]. Reactive power planning along with a voltage stability problem is presented in [13]. A modified interior power method is applied for optimal reactive power control in [14]. A GA based optimization algorithm is used for the allocation of static VAR compensators for a reactive power planning problem in [15]. A simulated annealing (SA) based optimization method is used to solve a multi-objective VAR planning problem in [16]. The effect of SVC's on an interconnected power system under normal and contingencies are investigated in [17]. Comparison of different evolutionary algorithms are presented in [18] for optimal reactive power flow. Heuristic methods are combined with optimization algorithms for voltage and reactive power control in [19]. An artificial bee colony based optimization technique for the optimal power flow problem and simultaneous reduction of active power loss in a large power network is described in [20]. Chance constrained programming based reactive power planning is investigated in [21]. How various optimization techniques can be used to overcome the different problems associated to reactive power planning is discussed in [22]. Solution for the security constrained reactive power planning problem is discussed in [23]. The Genetic algorithm based solution methodology is adopted for the power system network expansion planning in [24]. A successive linear programming technique is applied in [25] for a reactive power dispatch problem. A general quantum Genetic algorithm is used in [26] for reactive power and voltage control. Different strategies for simultaneous reduction of active power loss and improvement of a voltage profile is presented in [27]. A particle swarm based optimization technique for reactive power planning is presented in [28]. A Covariance matrix based evolutionary strategy for reactive power planning as well as enhancement of voltage stability is presented in [29]. Reactive power expansion planning is presented in [30]. An idea for optimal VAR planning in distribution feeders are presented in [31] where the locations of capacitors are determined by a heuristic approach. An AC modal of a Transmission Expansion Planning problem along with the reactive power planning solution technique is presented in [32]. A principle of the Genetic algorithm is described in [33]. In the present paper, the authors have proposed a new approach for the solution of the reactive power problem based on the detection of a weak bus by the FVSI method. The GA based optimization technique is then applied to determine the optimal setting of VAR sources. 


\section{Problem formulation}

The objective of the reactive power planning problem is to minimize the active power loss and the overall operating cost that includes cost due to energy loss and the investment cost of shunt VAR compensators installed at weak buses. Three approaches as Modal analysis, $L$-index and FVSI method of weak node detection are presented. Also the improvement of voltage stability is addressed along with the effective planning of the reactive power sources in the present work. Hence in the present work, reactive power planning is a multi-objective problem and different objective functions and constraints are formulated as follows:

\subsection{Minimization of active power loss}

Minimization of the active power loss in the transmission lines can be formulated as follows:

Minimize

$$
F_{1}=P_{\text {loss }}=\sum_{k=1}^{m} g_{k}\left[V_{i}^{2}+V_{j}^{2}-2 V_{i} V_{j} \cos \left(\delta_{i}-\delta_{j}\right)\right],
$$

where $P_{\text {loss }}$ denotes active power loss, $m$ is the number of lines, $g_{k}$ is the conductance of branch $k$ connected between $i^{\text {th }}$ and $j^{\text {th }}$ bus. $V_{i}$ and $V_{j}$ are the voltage magnitudes of the $i^{- \text {th }}$ and $j^{\text {th }}$ buses. $\delta_{\mathrm{i}}$ and $\delta_{\mathrm{j}}$ are the voltage phase angles of the $i^{\text {th }}$ and $j^{- \text {th }}$ bus respectively. $X$ is the vector of dependent variables.

$$
X=\left[P_{G}^{i}, V_{L}^{1}, \ldots . V_{L}^{n}, Q_{g}^{1} \ldots . . Q_{g}^{k}\right],
$$

where $P_{G}^{i}$ is active power generation at $i^{- \text {th }}$ bus, $V_{L}^{i}$ is the voltage of the $i^{- \text {th }}$ load bus, where $i=1,2,3, \ldots, n . n$ is the number of load bus. $Q_{g}^{i}$ is the reactive power output of the $i^{\text {th }}$ generator. where, $i=1,2, \ldots, k$. where $k$ is the number of generator bus.

The vector of the control variables are represented as:

$$
U=\left[P_{g}^{1} \ldots . P_{g}^{b}, V_{g}^{1} \ldots . V_{g}^{b}, Q_{c}^{1} \ldots . Q_{c}^{q}, t_{n}^{1} \ldots t_{n}^{t}\right] .
$$

$P_{g}^{i}$ is the active power generation at $i^{\text {th }}$ bus that remains unchanged as given by standard IEEE 30 bus test system. $V_{g}^{i}$ is the voltage of the voltage controlled bus, where $i=1,2, \ldots, b$. Here, $b$ is the total number of the generator bus. $Q_{c}^{i}$ is the shunt capacitor value installed at the $i-^{\text {th }}$ weak bus, where $i=1,2, \ldots, q . q$ is the total number of shunt VAR compensators or the total number of weak nodes. $t$ is the total number of tap changing transformer.

Now in the present problem, the main objective is to reduce the active power loss by proper coordination of the control variables as represented by Equation (3). Transformer tap setting arrangements and controlling of VAR output of generators do not require investment of additional cost but installation of shunt VAR compensators at weak nodes add extra cost to the operating cost. 
Hence objective of the reactive power planning problem becomes minimization of the cost which is the sum of the cost due to energy loss and the installation cost of shunt VAR compensators. Therefore, the objective function can be expressed as:

Minimize

$$
F_{1}=C_{1}+C_{2},
$$

where $C_{1}$ is the cost due to the energy loss, $C_{2}$ is the cost of the shunt capacitor. Fixed installation cost of capacitor $=1000 \$$, energy cost $=0.06 \$ / \mathrm{KWh}$, capacitor cost $/ \mathrm{kvar}=3 \$$, energy rate $=0.06 \times 100000 \times 8760$,

where

$$
C_{1}=P_{\text {loss }} \times \text { Energy rate. }
$$

\subsection{Voltage profile improvement}

For the secured operation of the power system and to provide a quality service to the consumer, maintaining a steady voltage profile even under increased loading condition is one of the challenging criteria for the power generation companies. The objective function can be formulated as:

Minimize

$$
F_{2}=\sum_{i=1}^{n_{b}}\left|V_{i}-V_{\text {specified }}\right|
$$

where, $n_{b}$ is the total number of buses and $V_{\text {specified }}$ is the specified bus voltage. $V_{\text {specified }}$ is taken as 1.0 p.u. The above mentioned objective functions are to be minimized under the following quality and inequality constraints.

\subsection{Equality constraints}

These constraints are load flow equations as described below:

$$
\begin{aligned}
& P_{G i}-P_{D i}-V_{i} \sum_{j=1}^{n_{b}} V_{j}\left[G_{i j} \cos \left(\delta_{i}-\delta_{j}\right)+B_{i j} \sin \left(\delta_{i}-\delta_{j}\right)\right]=0, \quad i=1,2, \ldots ., n_{b}, \\
& Q_{G i}^{\prime}-Q_{D i}-V_{i} \sum_{j=1}^{n_{b}} V_{j}\left[G_{i j} \sin \left(\delta_{i}-\delta_{j}\right)-B_{i j} \cos \left(\delta_{i}-\delta_{j}\right)\right]=0, \quad i=1,2, \ldots, n_{b} .
\end{aligned}
$$

Here $Q_{G i}^{\prime}=Q_{G i}+Q_{c i}$ and $Q_{c i}$ is shunt VAR compensation at the weak nodes provided by shunt VAR compensation, where $n_{b}$ is the total number of buses, $P_{G i}$ and $Q_{G i}$ are active and reactive power generation at the $i^{\text {th }}$ bus, $P_{D i}$ and $Q_{D i}$ are active and reactive power demand at the $i^{\text {th }}$ bus, $G_{i j}$ and $B_{i j}$ are the transfer conductance and susceptance between $i^{\text {th }}$ bus and $j^{\text {th }}$ bus respectively. 


\subsection{Inequality constraints}

Generator Constraints: The generator voltage magnitudes and reactive power outputs are constrained by design specifications. The lower and upper limits of generator voltage magnitude and reactive power outputs are given below:

$$
\begin{gathered}
V_{G i}^{\min } \leq V_{G i} \leq V_{G i}^{\max }, \quad i=1,2,3, \ldots, k, \\
Q_{G i}^{\min } \leq Q_{G i} \leq Q_{G i}^{\max }, \quad i=1,2,3, \ldots, k .
\end{gathered}
$$

Shunt VAR compensator constraints: Reactive power output of a shunt VAR compensator must be restricted within their lower and upper limits as follows:

$$
Q_{c i}^{\min } \leq Q_{c i} \leq Q_{c i}^{\max }, \quad I=1,2,3, \ldots, q .
$$

Transformer constraints: The upper and lower values for the transformer tap settings are limited by physical considerations and these are given below:

$$
T_{i}^{\min } \leq T_{i} \leq T_{i}^{\max }, \quad i=1,2,3, \ldots ., t .
$$

Security constraints: These include the constraints on voltage magnitudes at $p q$ buses and transmission line loadings. Voltage of each $p q$ bus must be within its operating limits. Line flow through each transmission line must be within its capacity limits. These are described as follows:

$$
\begin{gathered}
V_{L i}^{\min } \leq V_{L i} \leq V_{L i}^{\max }, \quad i=1,2,3, \ldots ., n, \\
S_{l i} \leq S_{l i}^{\max }, \quad i=1,2,3, \ldots ., m .
\end{gathered}
$$

\section{Determination of weak nodes}

Weak nodes or the weak buses are determined by following methods:

\subsection{Weak nodes detection by $L$-index method}

The $L$-index method is an approximate measure of closeness of the system to voltage collapse. The buses with the high $L$-index value are the vulnerable buses of the system and require VAR support to maintain a voltage profile when subjected to increased load demand. Though voltage stability enhancement can be done by minimizing $L$-index values at each bus of the power system but in the present work the $L$-index values are used only for the detection of weak nodes.

In the proposed work, weak buses are ranked according to their $L$-index values and some weak buses (here four buses) are selected according to high $L$-index values. Now the VAR support to the system will be provided by installation of a shunt VAR compensator at these 
buses. These along with the transformer tap setting arrangements and generators form control vector as shown in Table 1. A Genetic algorithm based optimization technique is applied for the optimal setting of the variables present inside the control vector. The $L$-index value of the $j^{\text {th }}$ bus is defined as:

$$
L_{j}=\left|1-\sum_{i=1}^{k} F_{j i} \frac{V_{i}}{V_{j}}\right|, \quad \text { where } \quad j=1,2,3, \ldots, n,
$$

where

$$
F_{j i}=-\left[Y_{1}\right]^{-1}\left[Y_{2}\right],
$$

where, $k$ is the number of $p v$ buses and $n$ is the number of $p q$ buses. $Y_{1}$ and $Y_{2}$ are the sub matrix of the system $Y$-bus obtained after segregating the $p q$ and $p v$ buses as

$$
\left[\begin{array}{l}
I_{p q} \\
I_{p v}
\end{array}\right]=\left[\begin{array}{ll}
Y_{1} & Y_{2} \\
Y_{3} & Y_{4}
\end{array}\right]\left[\begin{array}{c}
V_{p q} \\
V_{p v}
\end{array}\right] \text {. }
$$

\subsection{Weak nodes detection by modal analysis method}

A modal analysis method [3] uses reduced Jacobian matrix $J_{R}$ to analyze the system and provide both a relative proximity of the system to voltage instability, as well as the mechanism or key contributing factors to instability. We know that

$$
\left[\begin{array}{l}
\Delta P \\
\Delta Q
\end{array}\right]=\left[\begin{array}{ll}
\frac{\partial P}{\partial \theta} & \frac{\partial P}{\partial V} \\
\frac{\partial Q}{\partial \theta} & \frac{\partial Q}{\partial V}
\end{array}\right]\left[\begin{array}{l}
\Delta \theta \\
\Delta V
\end{array}\right]
$$

If active power $P$ is kept constant in Equation-(18) then

$$
\begin{gathered}
{\left[\begin{array}{c}
0 \\
\Delta Q
\end{array}\right]=\left[\begin{array}{ll}
J_{P \theta} & J_{P V} \\
J_{Q \theta} & J_{Q V}
\end{array}\right]\left[\begin{array}{c}
\Delta \theta \\
\Delta V
\end{array}\right],} \\
\Delta Q=J_{R} \Delta V,
\end{gathered}
$$

where $J_{R}$ is the reduced Jacobian system matrix and

$$
J_{R}=\left\lfloor J_{Q V}-J_{Q \theta} J_{P Q}^{-1} J_{P V}\right\rfloor .
$$

The reduced Jacobian $J_{R}$ gives direct relation between incremental changes of bus voltage magnitudes with the changes in reactive power injections. The modes of the power network can be defined by the eigenvalues and eigenvectors of $J_{R}$. Assume $J_{R}=\xi \wedge \eta$, where $\xi$ is the 
right eigenvectors matrix of $J_{R}, \eta$ is the left eigenvector matrix of $J_{R}, \wedge$ is the diagonal eigenvalue matrix of $J_{R}$

$$
J_{R}^{1}=\xi \wedge^{-1} \eta
$$

Incremental changes in reactive power and voltage are related by Equation (20). Substituting Equation (22) into Equation (20), we get

$$
\Delta V=\xi \wedge^{-1} \eta \Delta Q \quad \text { or } \quad \Delta V=\sum_{i} \frac{\xi_{i} \eta_{i}}{\lambda_{i}} \Delta Q,
$$

where $\lambda_{i}$ is the $i^{\text {th }}$ eigen value, $\xi_{i}$ is the $i^{\text {th }}$ column right eigen vector of $J_{R}, \eta_{i}$ is the $i^{\text {th }}$ row left eigen vector of $J_{R} \cdot \lambda_{i}, \xi_{i}$ and $\eta_{i}$ define the $i^{\text {th }}$ mode of the system.

The left and right eigenvectors corresponding to the critical modes in the system can provide information concerning the mechanism of voltage instability, by identifying the elements participating in these modes. The bus participation factor measuring the participation of the $k^{\text {th }}$ bus to the $i^{\text {th }}$ mode can be given as:

$$
P_{k i}=\xi_{k i} \eta_{i k}
$$

Bus participation factors corresponding to the critical modes can predict areas or nodes in the power system susceptible to voltage instability. Buses with large participation factors are defined as critical buses of the connected power network.

\subsection{Weak nodes detected by Fast Voltage Stability Index (FVSI) method}

A Fast Voltage Stability Index of lines is also used for the detection of weak nodes of a connected power system. The Fast Voltage Stability Index of a line can be approximately determined by

$$
F V S I_{i j}=\frac{4 Z^{2} Q_{j}}{V_{i}^{2} X},
$$

where $Z$ is the line impedance, $X$ is the line reactance, $Q_{j}$ is the reactive power at the receiving end, $V$ is the sending end voltage.

The line that exhibits FVSI closed to 1.00 implies that it is approaching its instability point. If FVSI goes beyond 1.00, one of the buses connected to the line will experience a sudden voltage drop leading to system collapse. FVSI values for all lines are calculated and the end nodes of lines are detected as vulnerable nodes for lines having high FVSI values.

\section{Genetic algorithms (GA) in brief}

In the present work, a Genetic algorithm is used as the optimization algorithm for reactive power planning. GA is used to determine the optimum magnitude of VAR sources. All the 
VAR sources are the control variables and appeared within a solution string in GA as shown in Fig. 1. Initially, sets of solution strings are created randomly in such a manner so that all the control variables have to be between their maximum and minimum limits as defined. Hence, in the initialization process of GA, a population vector consisting of several control variables is generated. Then the objective function is computed for every individual of the population. A biased roulette wheel [33] is created from the values obtained after computing the objective function for all the individuals of the current population.

Table 1. Solution vector consisting of control variables

\begin{tabular}{l|l|l|l|l|l|l|l|l}
\hline$Q_{g}^{1}$ & $\ldots$ & $Q_{g}^{k}$ & $Q_{c}^{1}$ & $\ldots$ & $Q_{c}^{q}$ & $t_{n}^{1}$ & $\ldots$ & $t_{n}^{t}$ \\
\hline
\end{tabular}

Thereafter the usual Genetic operation such as Reproduction, Cross-over and Mutation takes place. Two individuals are randomly selected from the current population for reproduction. Then crossover takes place with a probability close to one (here 0.8 ). Finally mutation with a specific probability (very low) completes one Genetic cycle and individuals of the same population with improved characters are created in the next generation. The objective function is then again calculated for all the individuals of the new generation and all the genetic operations are again performed and the second generation of the same population size is produced. This procedure is repeated till the final goal is achieved.

\section{Results and discussion}

A GA based optimization algorithm is applied on the IEEE 30 bus test system to solve the multi objective reactive power planning problem for different increased loading conditions. Here the GA based optimization algorithm is used for the proper co-ordination of the VAR generation of the generators, transformer tap setting arrangements and the reactive power of the shunt VAR compensators installed by modal analysis or the $L$-index method. The connection diagram of the IEEE 30 bus test system is shown in Fig. 1.

Variation of active power loss with the number of iterations for the base reactive loading, $125 \%$ of the base and 150\% of the base reactive loading is shown in Fig. 2, Fig. 3 and Fig. 4 respectively. Variation of operating cost with iteration for the base, $125 \%$ of the base and the $150 \%$ of the base reactive loading is shown in Fig. 5, Fig. 6 and Fig. 7 respectively. Active power loss and operating cost for different loading conditions by the three different methods of weak node detection is shown in Table 2. In the proposed method, maintaining a voltage profile within the acceptable limit is one of the important criteria. Maximum and minimum voltage magnitudes in different loading conditions for all the three methods of weak node detection is shown in Table 3. It is clear from Table 3 that by the effective planning of VAR sources a satisfactory voltage profile is maintained even under different increased loading cases. In Table 3, $V_{\min }$ is the voltage of the weakest node and $\mathrm{V}_{\max }$ is the voltage of the least weak node detected by the particular method of weak bus detection. Voltages of the most and 
least weak nodes of the three methods i.e., an $L$-index, modal analysis and FVSI methods are given in Table 3. The values of $V_{\min }$ and $V_{\max }$ are computed for different loading conditions when a GA based optimization technique is applied considering the modal analysis, $L$-index and FVSI method of weak node detection. From Table 2, it is observed that active power loss and operating cost is less in the FVSI method of detection than other two methods under all loading conditions. Again from Figs. 2-7, it is clear that if shunt VAR compensator locations are determined by the FVSI method and GA is then applied for the optimal setting of the reactive power sources including the shunt capacitor gives the most satisfactory result not only in terms of reduced active power loss but also in terms of system operating cost. This is observed for all loading conditions as shown in the Figs. 2-7, where GA based characteristics for different modes of weak node detections are plotted. Table 4 shows the value of reactive power sources obtained after applying the GA to the FVSI method of weak node detection.

It is to be mentioned that $19,18,26,14$ are the weak buses detected by Modal analysis and $28,12,26,24$ are the weak nodes detected by the $L$-index method. According to the FVSI method, weak nodes are 7, 17, 24 and 30 respectively.

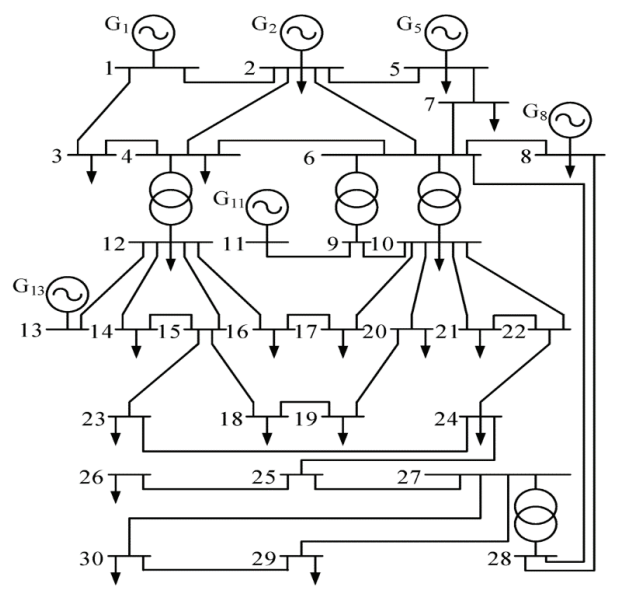

Fig. 1. Connection diagram of IEEE 30 bus test system

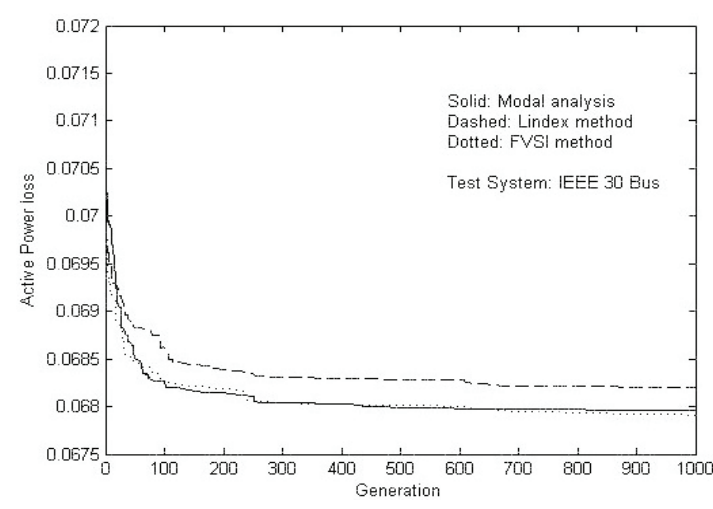

Fig. 2.Variation of active power loss with generation for base reactive loading using GA 


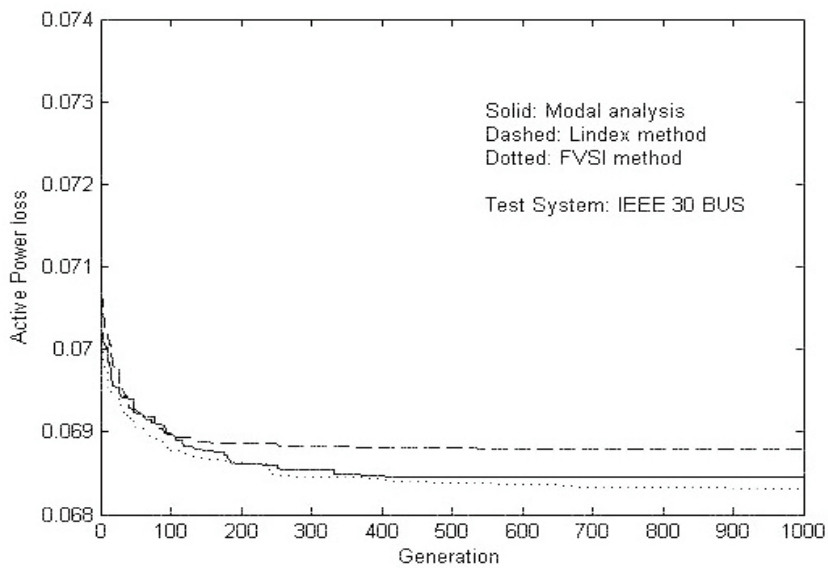

Fig. 3. Variation of active power loss with generation for $125 \%$ base reactive loading

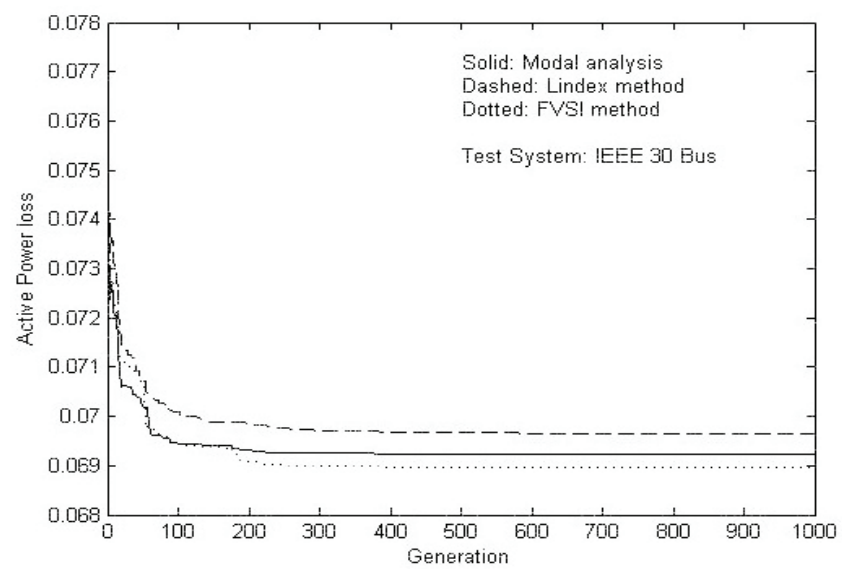

Fig. 4. Variation of active power loss with generation for $150 \%$ base reactive loading using GA

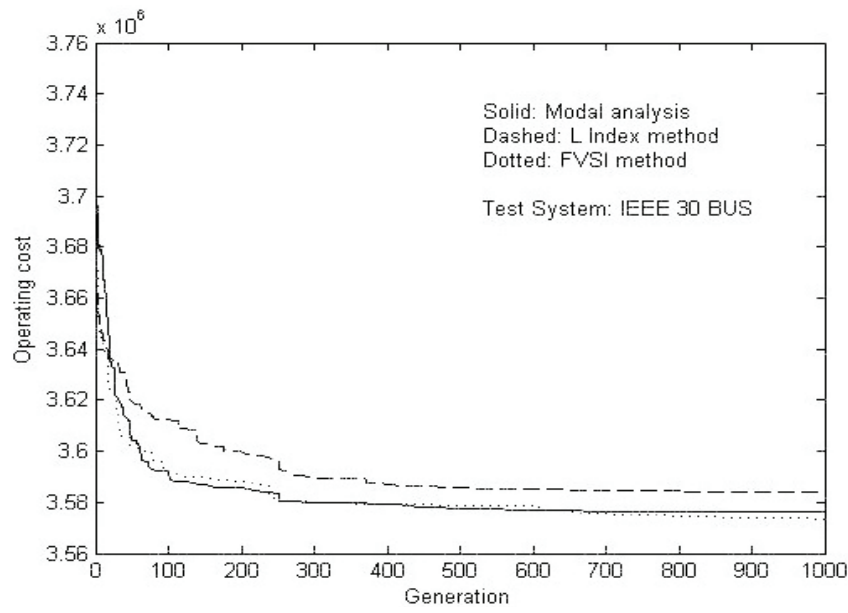

Fig. 5. Variation for operating cost with generation for base loading with GA 


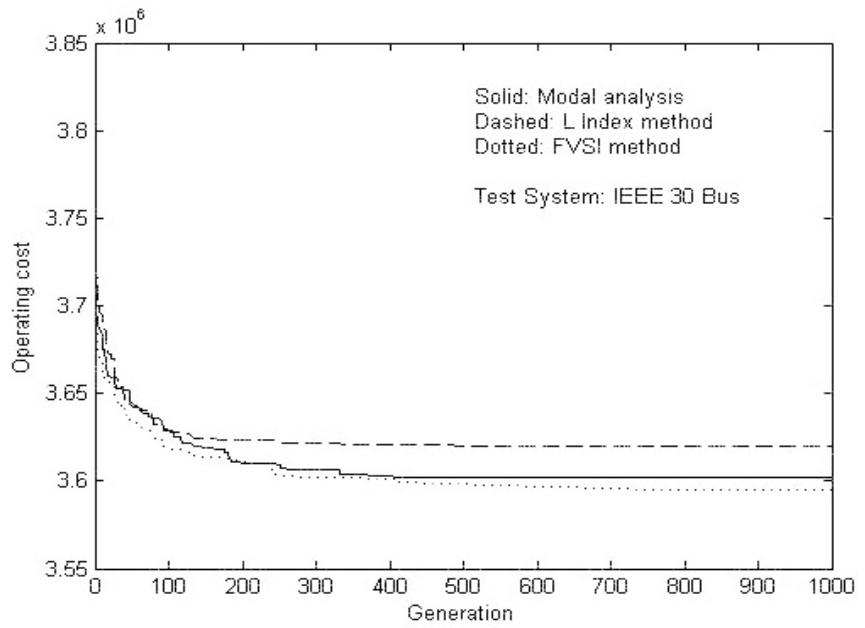

Fig. 6. Variation of operating cost with generation for $125 \%$ of base loading with GA

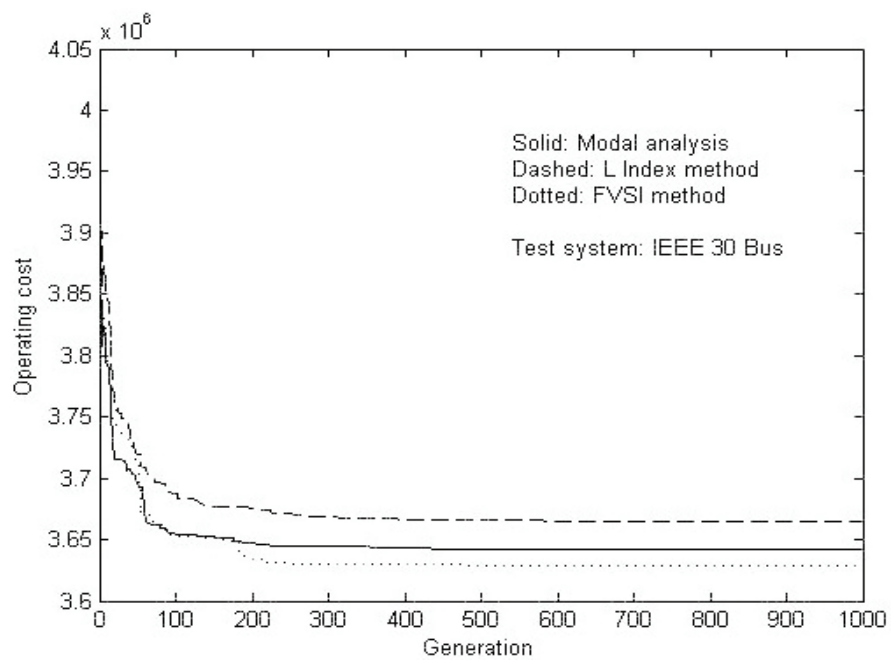

Fig. 7. Variation of operating cost with generation for $150 \%$ of base loading with GA

Table 2. Active power loss and operating cost for different loading in IEEE 30 bus system

\begin{tabular}{c|c|c|c|c|c|c}
\hline \multirow{2}{*}{$\begin{array}{c}\text { Reactive } \\
\text { system } \\
\text { loading } \\
\text { in p.u. }\end{array}$} & \multicolumn{2}{|c|}{$L$-index method } & \multicolumn{2}{c|}{ Modal analysis method } & \multicolumn{2}{c}{ FVSI method } \\
\cline { 2 - 7 } & $\begin{array}{c}\text { active } \\
\text { in p.u. } \\
\text { with GA }\end{array}$ & $\begin{array}{c}\text { operating cost } \\
\text { in (\$) with GA }\end{array}$ & $\begin{array}{c}\text { active power } \\
\text { loss in p.u. } \\
\text { with GA }\end{array}$ & $\begin{array}{c}\text { operating cost } \\
\text { in (\$) with GA }\end{array}$ & $\begin{array}{c}\text { active power } \\
\text { loss in p.u. } \\
\text { with GA }\end{array}$ & $\begin{array}{c}\text { operating cost } \\
\text { in (\$) with } \\
\text { GA }\end{array}$ \\
\hline$Q d$ & 0.0681 & $3.5886 \times 10^{6}$ & 0.0680 & $3.5763 \times 10^{6}$ & 0.0679 & $3.5733 \times 10^{6}$ \\
\hline $1.25 Q d$ & 0.0688 & $3.6197 \times 10^{6}$ & 0.0684 & $3.6017 \times 10^{6}$ & 0.0683 & $3.5945 \times 10^{6}$ \\
\hline $1.5 Q d$ & 0.0696 & $3.6442 \times 10^{6}$ & 0.0692 & $3.6422 \times 10^{6}$ & 0.0690 & $3.6287 \times 10^{6}$ \\
\hline
\end{tabular}


Table 3. Maximum and minimum voltage magnitude for different reactive loading in IEEE 30 bus test system

\begin{tabular}{c|c|c|c|c|c|c}
\hline \multirow{2}{*}{$\begin{array}{c}\text { Reactive } \\
\text { System } \\
\text { loading } \\
\text { in p.u. }\end{array}$} & \multicolumn{2}{|c|}{$L$-index method } & \multicolumn{2}{c|}{ Modal analysis method } & \multicolumn{2}{c}{ FVSI method } \\
\cline { 2 - 7 } & $\begin{array}{c}V_{\max }(\mathrm{GA}) \\
\text { in p.u. }\end{array}$ & $\begin{array}{c}V_{\min }(\mathrm{GA}) \\
\text { in p.u. }\end{array}$ & $\begin{array}{c}V_{\max }(\mathrm{GA}) \\
\text { in p.u. }\end{array}$ & $\begin{array}{c}V_{\min }(\mathrm{GA}) \\
\text { in p.u. }\end{array}$ & $\begin{array}{c}V_{\max }(\mathrm{GA}) \\
\text { in p.u. }\end{array}$ & $\begin{array}{c}V_{\min }(\mathrm{GA}) \\
\text { in p.u. }\end{array}$ \\
\hline$Q d$ & $1.0924(24)$ & $1.0030(28)$ & $1.0940(14)$ & $1.0154(19)$ & $1.0960(30)$ & $1.0073(7)$ \\
\hline $1.25 Q d$ & $1.0930(24)$ & $1.0010(28)$ & $1.0949(14)$ & $1.0012(19)$ & $1.0936(30)$ & $1.0071(7)$ \\
\hline $1.5 Q d$ & $1.0915(24)$ & $0.9995(28)$ & $1.0865(14)$ & $0.9993(19)$ & $1.0913(30)$ & $1.0072(7)$ \\
\hline
\end{tabular}

Table 4. Optimum values of the variables under different loading conditions using Genetic algorithm

\begin{tabular}{c|c|c|c}
\hline \multirow{2}{*}{$\begin{array}{c}\text { Reactive system } \\
\text { loading in p.u. }\end{array}$} & \multicolumn{3}{|c}{ FVSI method } \\
\cline { 2 - 4 } & $Q$ generation (p.u.) & OLTC Positions (p.u.) & $\begin{array}{c}\text { Shunt VAR compensators } \\
\text { (p.u.) }\end{array}$ \\
\hline \multirow{5}{*}{$Q d$} & $Q g(2)=0.1492$ & $\operatorname{tn}(11)=0.9$ & $\operatorname{Sh}(28)=0.0894$ \\
& $Q g(5)=0.2303$ & $\operatorname{tn}(12)=0.9102$ & $\operatorname{Sh}(12)=0.0750$ \\
& $Q g(8)=0.2286$ & $\operatorname{tn}(15)=0.9$ & $\operatorname{Sh}(24)=0.0295$ \\
& $Q g(11)=0.0183$ & $\operatorname{tn}(36)=0.9$ & $\operatorname{Sh}(26)=0.0479$ \\
& $Q g(13)=0.2056$ & $\operatorname{tn}(11)=0.9$ & $\operatorname{Sh}(28)=0.1116$ \\
& $Q g(2)=0.1914$ & $\operatorname{tn}(12)=0.9$ & $\operatorname{Sh}(12)=0.1106$ \\
& $Q g(5)=0.2731$ & $\operatorname{tn}(15)=0.9$ & $\operatorname{Sh}(24)=0.0359$ \\
& $Q g(8)=0.2993$ & $\operatorname{tn}(36)=0.9$ & $\operatorname{Sh}(26)=0.0555$ \\
& $Q g(11)=0.0529$ & & $\operatorname{Sh}(28)=0.1371$ \\
& $Q g(13)=0.2532$ & $\operatorname{tn}(11)=0.9063$ & $\operatorname{Sh}(12)=0.1420$ \\
& $Q g(2)=0.2288$ & $\operatorname{tn}(12)=0.9034$ & $\operatorname{Sh}(24)=0.0428$ \\
& $Q g(5)=0.3214$ & $\operatorname{tn}(15)=0.9$ & $\operatorname{Sh}(26)=0.0776$ \\
& $Q g(8)=0.2999$ & $\operatorname{tn}(36)=0.9$ & \\
\hline \multirow{5}{*}{$1.5 Q d$} & $Q g(11)=0.1677$ & & \\
& $Q g(13)=0.27$ & &
\end{tabular}

\section{Conclusions}

This paper shows a new method of reactive power planning where weak nodes of capacitor placement is determined by the FVSI method. The program on a Genetic algorithm is developed by the authors in the MATLAB 13a environment and is then applied for optimal setting of all VAR sources including the shunt VAR compensators. GA based allocation of VAR sources with the FVSI method of weak node detection gives a better result than all other methods of weak node detection. It is observed that active power loss and system operating cost 
are lesser in the FVSI method than in other two methods such as modal analysis and the $L$-index method. It is also to be mentioned that substantial reactive power support is available for maintaining good quality of voltage at all the nodes even at increased loading conditions. Therefore, the main contribution of this present work is the determination of the proper method of weak node detection and the authors have also established that the maximum benefit can be achieved if VAR sources are allocated on this basis. So, this FVSI based optimal allocation of VAR sources by the Genetic algorithm can be a new tool for reactive power planning.

\section{References}

[1] Deeb N.I., Shahidehpour S.M., Cost minimization in allocation of reactive power source, International Journal Electric Power and Energy System, vol. 49, no. 4, pp. 263-270 (1990).

[2] Yehia M., Ghandour I., Saidy M., Stroev V.A., Reactive power optimization in large scale power system, International Journal Electric Power and Energy System, vol. 14, no. 4, pp. $276-283$ (1992).

[3] Gao B., Morison G. K., Kundur P., Voltage stability evaluation using Modal analysis, vol. 7, no. 4, pp. 1529-1542 (1992).

[4] Chen Y.L., Weak bus oriented reactive power planning for system security, IEE Proc. Generation, Transmission, and Distribution, vol. 143, no. 6, pp. 541-545 (1996).

[5] Lai L.L., Ma J.T., Practical application of evolutionary computing to reactive power planning, IEE Proc. Generation, Transmission, and Distribution, vol. 145, no. 6, pp. 753-758 (1998).

[6] Jwo W.S., Liu C.W., Liu C.C., Hsiao Y.T., Hybrid expert system and simulated annealing approach to optimal reactive power planning, IEE Proc.-Generation, Transmission Distribution, vol. 142, no. 4, pp. (1995).

[7] Parker C.J., Morrison I.F., Sutanto D., Application of an Optimization Method for Determining the Reactive Margin from Voltage Collapse in Reactive Power Planning, IEEE Transaction Power System, vol. 11, no. 3, pp. 1473-1481 (1996).

[8] Mantovani J.R.S., Garcia A.V., A Heuristic Method for Reactive Power Planning, IEEE Transaction Power System, vol. 11, no. 1, pp. 68-74 (1996).

[9] Liu C.W., Jwo W.S., Liu C.C., Hsiao Y.T., A Fast Global Optimization Approach to VAR Planning for the Large Scale Electric Power Systems, IEEE Transaction Power System, vol. 12, no. 1, pp. 437-447 (1997).

[10] Vaahedi E., Mansour Y., Li W., Tam J., Sun D., Maratukolam D., Evaluation of existing optimal VAR planning tools on utility systems, IEE Proc. Generation, Transmission and Distribution, vol. 145, no. 6, pp. 663-668 (1998).

[11] Mohamed A.H.E.S., Rule-based approach for real-time reactive power control in interconnected power systems, Expert Systems with Applications, vol. 14, no. 3, pp. 355-360 (1998).

[12] Lee K.Y., Yang F.F., Optimal Reactive Power Planning Using Evolutionary Algorithms: A Comparative Study for Evolutionary Programming, Evolutionary Strategy, Genetic Algorithm, and Linear Programming, IEEE Transaction Power System, vol. 13, no. 1, pp. 101-108 (1998).

[13] Chattopadhyay D., Chakrabarti B.B., Reactive Power Planning Incorporating Voltage Stability, International Journal Electric Power and Energy System, vol. 24, no. 3, pp. 185-200 (2002).

[14] Zhua J.Z., Xiong X.F., Optimal reactive power control using modified interior point method, Electric Power System Research., vol. 66, no. 2, pp. 187-192 (2003).

[15] Yousefi G.R., Seifi H., Sepasian M.S. et al., A new reactive power planning procedure for Iranian Power Grid, Electric Power Systems Research, vol. 72, pp. 225-234 (2004).

[16] Chen Y.L., Ke Y.L., Multi-objective VAR planning for large-scale power systems using projectionbased two-layer simulated annealing algorithms, IEE Proc. Generation, Transmission and Distribution, vol. 151, no. 4, pp. 555-560 (2004). 
[17] Ibrahim E., Abusorrah A., Optimum Firing of SVC's for Normal and Emergency Reactive Power Control, Electric Power Components and Systems, vol. 32, no. 8, pp. 785-800 (2004).

[18] Liang C.H., Chung C.Y., Wong K.P., Duan X.Z., Comparison and improvement of evolutionary programming techniques for power system optimal reactive power flow, IEE Proc. Generation, Transmission and Distribution, vol. 153, no. 2, pp. 228-236 (2006).

[19] Bie Z.H., Song Y.H., Wang X.F. et al., Integration of algorithmic and heuristic techniques for transition-optimized voltage and reactive power control, IEE Proc. Generation, Transmission and Distribution, vol. 153, no. 2, pp. 205-210 (2006).

[20] Ayan K., Kilic U., Artifical bee colony algorithm solution for optimal reactive power flow, Applied Soft Computing, vol. 12, no. 5, pp. 1477-1482 (2012).

[21] Yang N., Yu C.W., Wen F., Chung C.Y., An investigation of reactive power planning based on a chance constrained programming, International Journal Electric Power and Energy System, vol. 29, no. 9, pp. 650-656 (2007).

[22] Raju G.K.V., Bijwe P.R., Reactive power/Voltage control in distribution system under uncertain environment, IET Proc. Generation, Transmission, and Distribution, vol. 2, no. 5, pp. 752-763 (2008).

[23] Parida S.K., Singh S.N., Srivastava S.C., A Hybrid Approach Toward Security-constrained Reactive Power Planning in Electricity Markets, Electric Power Components and Systems, vol. 36, no. 6, pp. 649-663 (2008).

[24] Sadegheih A., Drake P.R., System network planning expansion using mathematical programming, genetic algorithms and tabu search, Energy Conversion and Management, vol. 49, no. 6, pp. 1557-1566 (2008).

[25] Gomesa M.H., Saraivab J.T., A market based active/reactive dispatch including transformer taps and reactor and capacitor banks using Simulated Annealing, Electric Power Components and Systems, vol. 79, no. 6, pp. 959-972 (2009).

[26] Vlachogiannis J.G., Ostergaard J., Reactive power and voltage control based on general quantum genetic algorithms, Expert Systems with Applications, vol. 36, no. 3, part 2, pp. 6118-6126 (2009).

[27] Zhu J., Cheung K., Hwang D., Sadjadpour A., Operation Strategy for Improving Voltage Profile and Reducing System Loss, IEEE Transaction Power Delivery, vol. 25, no. 1, pp. 390-397 (2010).

[28] Zhong L.H., Zhong C.H., Zheng Y., A novel reactive power planning method based on improved particle swarm optimization with static voltage stability, European Transaction Electric Power, vol. 20, no. 8, pp. 1129-1137 (2010).

[29] Jeyadevi S., Baskar S., Iruthayarajan M.W., Reactive power planning with voltage stability enhancement using covariance matrix adapted evolution strategy, European Transactions on Electrical Power, vol. 21, no. 3, pp. 1343-1360 (2011).

[30] Jabr R.A., Optimization of Reactive Power Expansion Planning, Electrical Power Component System, vol. 39, no. 12, pp. 1285-1301 (2011).

[31] Hamouda A., Zehar K., Stability-index based method for optimal VAR planning in distribution feeders, Energy Conversion and Management, vol. 52, no. 5, pp. 2072-2080 (2011).

[32] Hooshmand R.A., Hemmati R., Parastegari M., Combination of AC Transmission Expansion Planning and Reactive Power Planning in the restructured power system, Energy Conversion and Management, vol. 55, pp. 26-35 (2012).

[33] Goldberg D.E., Genetic Algorithms, Pearson Education India (2006). 